\title{
27. Improving the Basin Plan: Options for consideration ${ }^{1}$
}

\author{
Mike Young
}

\section{Re-Engaging with Basin Communities}

Given the untidy release of the Guide to the proposed Basin Plan, the future depends on both the way the next phase of consultation processes are run and the policy decisions taken as the process runs forward. From an administrative perspective, many of the structural-adjustment and environmental-water management decisions lie beyond the remit of the Murray-Darling Basin Authority (MDBA). In recognition of this reality, this chapter begins by recommending that the new Chair of the Authority be given responsibility for coordinating development of a whole-of-government approach to the resolution of the Basin's problems and development of the Basin Plan.

There are many ways to implement the next consultation phase and restore community confidence; one way is to prepare a green paper. Rather than going over old ground, this green paper would identify the suite of policy choices that needs to be resolved in the course of preparing a Plan. Short, rather than long, this green paper could then be used to open dialogue and truly engage with the Basin. Those responsible for preparing this green paper would need to draw upon the advice submitted to the MDBA and to parliamentary inquiries that have considered the range of issues before basin communities. Once community confidence has been restored and they have been given time to respond, a white paper could be used to present the Government and the Authority's collective position on the policy changes that need to be made to restore health to the Basin.

\section{Background}

The Guide to the proposed Basin Plan released by the Murray-Darling Basin Authority (MDBA) represents one of the first attempts by a government to develop a management plan for a large river system that has its roots in scientific

1 The opportunity to discuss and develop the ideas presented in the chapter with Jim McColl is acknowledged with appreciation. 
analysis. The approach taken was to trust the science and then present a strong set of recommendations to the community. As indicated elsewhere in this book, the approach taken by the Authority and the way it engaged with those who live in the Murray-Darling Basin failed to gain the trust and support of this community.

Rather than criticising the approach taken by the Authority and the communication mistakes made, this chapter focuses on institutional opportunities to develop and deliver a Plan that communities can embrace.

The recommendations made enable greater use of community skills and knowledge, encourage innovation in the management of environmental water and provide funding for adjustment. If these recommendations are adopted then the cost of fixing the Basin's problems in an equitable and efficient manner will be less.

In addition, it is recommended that the approach taken to the definition of sustainable diversion limits (SDLs) be changed. Consistent with the National Water Initiative, it is recommended that the environment's share of inflows into the system should be defined using an entitlement-based rather than a rulesbased planning approach. The result is a regime that allows further adjustments to be made without the compulsory acquisition of water from entitlementholders.

\section{Ways Forward}

\section{Giving the Environment an Entitlement}

The first opportunity to improve the Basin Plan identified in this chapter is to change the way it is proposed to define SDLs.

In the Guide to the proposed Basin Plan, the SDL is defined quantitatively as a long-term average - a volume. ${ }^{2}$ The volume chosen to define the SDL is a longterm average amount that can be diverted, reduced by 3 per cent to adjust for the MDBA's assessment of that part of the predicted effects of climate change not included in regional plans.

2 At page 103, the Guide (MDBC 2010) says: 'Long term sustainable limits (SDLs) represent the volume of water that is available for consumptive use (irrigation, town water supplies, industry, etc) after the environment has received what it requires.' The amount the environment requires determines the limit and, hence, may not be changed by purchasing entitlements from a consumptive-water user. 
If this approach is taken and once the implementation of the Basin Plan and regional plans is completed (in 2019), any further reduction of SDLs is possible only via the compulsory reduction of entitlements and the payment of compensation. ${ }^{3}$

This situation arises because, under the proposed Basin Plan, all water secured or held for the environment is defined as being outside the SDL. Further, Section 4 of the Water Act 2007 defines

the environmentally sustainable level of take for a water resource...[as] the level at which water can be taken from that water resource which, if exceeded, would compromise:

(a) key environmental assets of the water resource; or

(b) key ecosystem functions of the water resource; or

(c) the productive base of the water resource; or

(d) key environmental outcomes for the water resource.

Significantly - and if this quantitative approach is taken to the definition of a SDL - the words 'if, exceeded, would compromise' mean that water held for the environment is not part of the SDL. Once the Basin Plan is in place and regional plans approved, it will no longer be possible to reduce the amount of water being used by purchasing more water entitlements for the environment. The only way to increase the environment's entitlement or share of inflows is to revise the SDL for a region by either

- paying compensation for the reduction in the value of all entitlements in the system

- compulsorily acquiring a proportion of each entitlement.

The way out of this surprising - and presumably unintended - feature of the Water Act is to use an entitlement-based rather than a quantitative approach to the definition of SDLs. Fortunately, this is possible because Section 23(2) of the Water Act states that:

A long-term average sustainable diversion limit for the Basin water resources, for the water resources of a particular water resource plan area or for a particular part of those water resources may be specified:

(a) as a particular quantity of water per year; or

3 See the bottom of page 154 in the Guide (MDBA 2010) and Division 4 of the Water Act. 
(b) as a formula or other method that may be used to calculate a quantity of water per year; or

(c) in any other way that the Authority determines to be appropriate.

Section 23(2)(c) makes it clear that an SDL may be defined in the most appropriate way the MDBA can identify. In this chapter, it is argued that the most appropriate way is to define the nature of the portfolio of entitlements that needs to be held by the environment in each region. There are a number of advantages of taking this entitlement-based approach.

1. Consistent with Section 23(2) of the Water Act, the Basin Plan would require that regional plans establish rules for the allocation of water to each type of entitlement in a region. The minimum proportion of each type of entitlement to be held by the environment would then be specified. In areas where water in one region is easily traded to another, this proportion should be specified in a manner that enables the goal to be reached by securing access to entitlements in other areas. The proportion specified should be a minimum. If subsequent research shows that the portfolio of entitlements held in the environment's interest is inadequate, the policy should state that more water entitlements should be acquired in a timely manner. No complex administrative revision of the SDL would be necessary.

2. The entitlement-based approach enables iteration towards a solution with a focus on ways to improve the efficiency of environmental-water use. If this approach is taken, the Basin Plan will need to indicate the minimum portfolio of shares to be acquired in each region, a time frame for its acquisition and a target portfolio to be acquired if no ways to improve the efficiency in the delivery of required environmental outcomes can be found.

3. The approach also makes it possible for environmental managers to manage supply risk more effectively. A South Australian environmental manager might, for example, conclude that the most cost-effective strategy would be to secure a portfolio of entitlements that included some general-security entitlements from New South Wales and some low-security entitlements from Victoria. ${ }^{4}$ Similarly, an environmental-water manager might decide to sell some water allocation and use the money received to pay for the installation of a control gate that would allow the much more efficient use of environmental water.

4. An additional advantage of the property-right approach is the fact that accounting risks are distributed in proportion to the number of the entitlements held. If, for example, estimates of the amount of water being

4 This would have the additional advantage that it would enable an SA environmental-water manager to carry forward water from one season to the next. 
intercepted by a forest are too conservative then all water users, including the environment, will have less water made available to them. As a result, environmental managers and irrigators have a joint interest in ensuring that this problem is solved. When a quantitative approach is taken, however, the SDL remains the same and the amount of water left to the environment is reduced by the size of the underestimate in the amount of water intercepted. In short, when a quantitative-planning approach is taken, the environment takes all the downside risk. ${ }^{5}$ When an entitlement-based approach is taken, both sides have an interest in ensuring that water-accounting problems - such as failure to account adequately for the adverse effects of forest plantations or groundwater use-are fixed. The environment is given an entitlement equivalent to that given to other users. The approach forces governments to allocate water to the environment whenever they allocate water to any user holding an equivalent entitlement.

5. Amongst other things, this entitlement-based approach focuses discussion on the best way to manage environmental water and makes it difficult for people to add up the SDLs. Conceptually, one should add quantitative SDLs together only when the regions are closely connected and have similar flow distributions. Amongst other things, the Basin Plan needs to recognise that flows in the Darling River are many thousand times more variable than those in the Murray River system.

6. Another consideration is the fact that property-right-based approaches reverse the role of the entitlement system and regional plans. When a property-right approach is taken, regional plans do not need to be used to work out how to partition water between the environment and other entitlement-holders on a day-by-day basis. The environment's share is determined by the nature of the entitlements held not the SDL. As a result, regional plans can be made much more strategic and flexible in their orientation. Less prescription is necessary and more attention can be given to the nature of the outcomes required.

7. The proposed entitlement-based approach also deals with climate change and variability in a much more transparent manner. This is especially the case in the southern connected River Murray system, where the MDBA is required to establish a conveyance reserve to ensure that enough water is available to supply critical human needs throughout the system and generally maintain the river at a minimum level. ${ }^{6}$ As a result of this arrangement, if an entitlement-based approach is taken, a built-in mechanism for managing

5 Irrigators will argue that they would prefer the existing quantitative regime, as this is what they understand. They also understand that when a quantitative regime is put in place, the impact of the majority of accounting risks falls on the environment.

6 Strictly, Section 86A(4) of the Water Act requires conveyance only as far as Wellington, South Australia. 
the effects of adverse climate change is always in place; as the amount of water in the system reduces, a larger proportion of water is allocated to the environment.

In summary, by taking an entitlement-based sharing approach and defining the environmental water requirement (EWR) as the portfolio of entitlements to be held for the environment in each region, accounting risks can be managed more effectively, the need to compulsorily acquire water in the future can be avoided and a more flexible approach can be taken to the resolution of the Basin's problems.

Significantly, whenever more water is needed for the environment, the need to switch on the risk-allocation provisions of the Water Act that require the Commonwealth to pay compensation is avoided. The option to purchase entitlements for the environment from willing sellers is preserved. The compensation provisions set out in Section 77 of the Water Act, titled 'Payments to water access entitlement holders', would never need to be used.

\section{Maximising Innovation: A regional approach}

The next opportunity identified in this chapter is to enable greater use of local knowledge and skills in the management and use of environmental water.

Under the current administrative regime, water entitlements acquired for the environment are being transferred to the Commonwealth Environmental Water Holder (CEWH). The result is a regime in which, ultimately, the CEWH will have access to about 35 per cent of all water entitlements in the Basin. Once this process is completed, States and local communities will have to negotiate access to this water. They are not trusted to be able to get this right.

The alternative (recommended) approach is to transfer a significant proportion of the CEWH's entitlements to regional environmental-water trusts (see Young 2010). This approach builds upon the European concept of 'subsidiarity' - the notion that a central authority should be responsible only for those functions that cannot be handled more effectively at a regional level. While some environmental water needs to be held centrally to ensure that basin-wide tradeoffs can be managed and opportunities to synchronise inter-regional initiatives pursued, in practice, much of this water will always be needed for use within each region.

In the case of environmental-water management, it is virtually impossible for any one person or entity to be aware of environmental needs and opportunities throughout the Basin. Local knowledge is needed and-as experience in Oregon's Water Trust in the United States has demonstrated-is best achieved by giving local trusts absolute control of water entitlements for use in their 
region. Using existing laws, the Commonwealth Government could decide to establish a set of regional environmental trusts and lease some of the CEWH's entitlement to these trusts on a long-term basis.

When a significant proportion of a region's environmental-water entitlement is held in a regional environmental-water trust, local managers can plan with confidence and explore innovative options. A local manager, for example, may decide to water an area for three weeks and set aside enough water to guarantee that this area can be rewatered the following year.

When a regional approach to environmental-water management is taken, there is greater opportunity to take advantage of local knowledge. Local pride in the extent of outcomes achieved per unit of water allocated to the environment emerges. Tension dissipates. More effort goes into the delivery of outcomes and less into negotiation with a centralised bureaucracy (Young 2010).

If knowledge about how to distribute environmental-water entitlements throughout the Basin is insufficient to do this on a permanent basis then, as a transitional arrangement, the Commonwealth could establish an environmentalwater management trust in each region and instruct the $\mathrm{CEWH}$ to lease about 50 per cent of water being held by this entity to these regional trusts for, say, 10 years.

In summary, there is an opportunity to establish regional environmental trusts throughout the Basin, allocate entitlements to them and make them both responsible and accountable for wise use of this water.

\section{Funding Adjustment}

The next opportunity to consider is the question of how best to assist communities to adjust to a regime under which accounting and supply risks are shared more evenly between the environment and all other water users. It is current government policy to resolve the over-allocation problem by

- purchasing water entitlements for the environment only from people prepared to sell some of their entitlement at the current market prices ${ }^{7}$

- investing in projects that, by making irrigation more efficient, enable 50 per cent of the savings made to be transferred as an entitlement to the CEWH.

Typically, the price paid per megalitre of entitlement secured through an infrastructure project is two to three times higher than that paid for a megalitre of water purchased by the Commonwealth. Many criticisms have and will continue to be made of this approach.

7 It is current Commonwealth policy to try to purchase water entitlements without increasing market prices. 
One of the criticisms made is that these two mechanisms do not address the interests of the communities likely to be adversely affected by the transfer of water entitlements from irrigators to the environment. Another criticism is the observation that government investment in projects that improve the efficiency of water use is best described as a 'subsidy' that disadvantages irrigators who have upgraded infrastructure at their own expense. Moreover, several people have observed that the $\$ 8.9$ billion allocated for the purchase of water and investment in infrastructure is insufficient to secure the water needed to achieve the SDL limits proposed by the MDBA. There is, however, sufficient money to achieve the proposed SDLs and make some money available to assist communities to adjust if most of this money is used to acquire water entitlements for the environment.

Instead of directly funding infrastructure projects, the Commonwealth Government could decide to take a broader regional approach and plan to assist all communities to adjust to the new regime. If this decision is taken then it will be necessary to establish a set of regional-development funds and make contributions to these funds as water entitlements are acquired for the environment. Acting on the assumption that the impact on communities of water-entitlement acquisition for the environment is likely to increase as more and more water is purchased, the size of the contribution made to a fund per megalitre of water purchased could be increased as the number of entitlements purchased from a region increases.

Within broad guidelines, each region would then be free to determine how best to allocate this money and determine how much should be invested in projects that improve irrigation efficiency, how much should be invested in the restructuring of supply systems and how much in building the infrastructure needed to enable those adversely affected by the purchase of water for the environment to pursue new opportunities. ${ }^{8}$ If this approach is taken, the resolution of over-allocation problems could be speeded up through the use of a reverse tender or other similar buyback arrangement that offers to pay more than the current very low prices being offered.

In summary, rather than investing in projects that improve irrigation efficiency, consideration could be given to the establishment of regional-development funds that give all members of a community an opportunity to apply for and receive financial assistance.

8 A warning needs to be issued: a review of Australian experience with 10 eras of adjustment experience found that, despite the best intentions, most adjustment-assistance programs have had severe unintended consequences that undermine most if not all of the benefits sought. Past programs have tended to impede rather than expedite change (McColl and Young 2006, 2007). 


\section{Carry Forward: Reducing the amount of water needed for the environment}

Unfortunately, the last opportunity to improve the Basin Plan identified in this chapter would require amendment of the Water Act and agreement among all the governments involved in the Murray-Darling Basin. Given that the current Commonwealth Government does not hold a majority in either house of Parliament, any attempt to amend the Water Act is likely to be fraught with problems; nevertheless, this last opportunity is worth exploring. The opportunity is to amend the Water Act so that the only restriction on the amount of water that entitlement-holders and States can carry forward from one year to the next would be the presence of adequate storage space in dams. Amendment of the Water Act to allow all entitlement-holders and states to carry forward water from year to year would significantly reduce the amount of water that needs to be secured for the environment.

From the perspective of an environmental manager, water stocks need to be managed so as to enable the creation of many small and medium-scale floodlike conditions. In a regime under which allocations are made in proportion to the number of entitlements held, this is most efficiently achieved if the only restrictions on the amount of water that may be carried forward are those necessary to offset evaporative losses and manage dam spills. Amendment of the Water Act and of interstate water-sharing arrangements in the River Murray system is needed to do this.

In Queensland, carry-forward policies appropriate to environmental needs are already in place. In Queensland's regulated river systems, under what is known as a continuous accounting, entitlement-holders may carry forward as much water from year to year as they like - provided evaporative losses are accounted for and there is enough dam space. In Victoria and New South Wales, however, carry forward is allowed only up to 100 per cent of entitlement; stockpiling of more than one year's maximum allocation is not allowed. Under normal (Tier 1) conditions, South Australia is not allowed to carry forward water from one year to the next for anything other than urban water supply purposes. In addition, the amount of water that Victoria and New South Wales are required to release into South Australia is limited.

In summary, the Water Act and interstate water-sharing arrangements could be amended to allow the unrestricted carry forward and transfer of water from one year to the next provided evaporative losses are accounted for and there is adequate dam space. In addition, the Water Act could be amended to allow South Australia complete freedom in deciding when to use any water that it has carried forward from one year to the next. 


\section{Concluding Comments}

In this chapter, four opportunities to improve the Basin Plan are identified. The first of these is to use a different mechanism to specify the SDL set for each region. The approach enables iteration towards a sustainable water-sharing regime for the Basin and removes all consideration of the need to compulsorily acquire water entitlements for the environment. The second opportunity recommends establishment of regional environmental-water trusts so that greater use can be made of local knowledge and opportunities to improve the management of environmental water are greater. The third identifies an opportunity to establish regional-development funds so that adverse effects of existing arrangements on the irrigation industry and on communities are avoided. The last opportunity would allow the more efficient inter-temporal management of storage for environmental purposes and, hence, reduce the size of the portfolio of water entitlements that needs to be secured for the environment.

In closing, it is important to draw attention to the fact that each of the recommendations made in this chapter would allow more effective use of the Basin's water resources and make it possible to achieve the same environmental outcomes with less water. As noted in the chapter by Connell (this volume), under existing arrangements, it is possible to acquire sufficient water to solve all the Basin's environmental problems.

The main purpose of the Basin Plan is to reduce the size of the portfolio of water entitlements that needs to be secured for the environment in each region and thereby reduce the cost of solving the Basin's problems.

\section{Bibliography}

McColl, J. and Young, M. 2006, 'Drought and structural adjustment', Farm Policy Journal, vol. 3, no. 2, pp. 13-21.

McColl, J. C. and Young, M. D. 2007, Managing change: Australian structural adjustment lessons for water, Report No. 16/05, CSIRO Land and Water, Canberra.

Murray-Darling Basin Authority (MDBA) 2010, Guide to the proposed Basin Plan, Murray-Darling Basin Authority, Canberra.

Young, M. D. and McColl, J. C. 2008, A Future-Proofed Basin: A new water management regime for the Murray-Darling Basin, University of Adelaide, SA.

Young, M. D. 2010, 'Managing environmental water' , in J. Bennett, R. T. Kingsford, R. H. Norris and M. D. Young, Making decisions about environmental water allocations, Research Report, Australian Farm Institute, Surry Hills, NSW. 